\title{
Self-enforcing norms and efficient non-cooperative collective action in the provision of public goods
}

\author{
Kai A. Konrad • Wolfgang Leininger
}

Received: 3 June 2009 / Accepted: 8 January 2010 / Published online: 27 January 2010

(C) The Author(s) 2010. This article is published with open access at Springerlink.com

\begin{abstract}
We show how norms can solve the distributional conflict inside a group in an anarchic environment and yield efficient coordination of collective action in a conflict with an external competitor. The equilibrium of the fully non-cooperative game with finite horizon has two interesting features. First, one of the players assumes a central role that resembles the role of the 'big-man' in some primitive stateless societies. Second, the group members' contributions to collective output and the payments from the big-man to these members seemingly look like reciprocal behavior, even though they are driven by narrowly selfish preferences.
\end{abstract}

Keywords Free-riding · Collective action · Anarchy · Distributional conflict · War · Norms · Big-man

JEL Classification D72 $\cdot$ D74 $\cdot$ H11 $\cdot$ H41

\section{Introduction}

Anthropologists have studied governance regimes for a variety of primitive societies. Sahlins (1963) described a particularly interesting structure for a number of Melanesian tribes. ${ }^{1}$ In these tribes ordinary members provide productive services, whereas a wealthy player (the

\footnotetext{
${ }^{1}$ Similar governance structures and the importance of generous "wealthy men" are reported, for instance, for the Kapauku Papuans by Benson (1988).

K.A. Konrad $(\varangle)$

Max Planck Institute for Intellectual Property, Competition an Tax Law, Munich, Germany e-mail: kai.konrad@ip.mpg.de

W. Leininger

Department of Economics, University of Dortmund (TU), 44221, Dortmund, Germany

e-mail: wolfgang.leininger@udo.edu
} 
'big-man') is involved in extensive and unconditional gift giving. ${ }^{2}$ Sahlins's report about a functioning state-less society which coped with the problem of collective good provision and internal peace is the starting point of our analysis. While Sahlins interprets some of the activities among members of the tribe as governed by reciprocity, we analyse a noncooperative game that adopts key elements of Sahlins's report, but does not follow Sahlins's interpretation of exchange as reciprocal behavior. Instead, we develop a structure that has a non-cooperative equilibrium in which members of the stateless society ${ }^{3}$ (the 'clan' in what follows) make efficient contributions to collective action and abstain from internal fighting. Our approach reveals that what has been seen as evidence of reciprocating behavior (Sahlins 1963: 293) may simply be a sequence of actions in a subgame perfect equilibrium among narrowly selfish players. Norms about adequate contributions to group output and adequate wealth distributions play the role of coordination devices that allow players to choose this efficient equilibrium from among a set of equilibria. Hence, although our clan formally lives in a state of anarchy, it avoids internal conflict and achieves a self-enforcing solution to the public good provision problem.

The cornerstones of our game are as follows. Clan members first decide on their contributions to the collective action. Then one member may decide to make donations to other group members. We may call this player the 'big man'. The big man does not control any enforcement technology, but he has a sufficient amount of wealth to be able to make considerable donations. Then the members of the group decide whether to fight inside the group. At this stage there are multiple equilibria, with a peaceful and a most resource wasteful fighting equilibrium among these. Behavior on earlier stages triggers the choice of equilibrium in this later stage as follows. If the members of the organization make contributions and the 'big-man' makes donations that are in accordance with what the members of the organization consider appropriate, then all members of the organization may choose to abstain from internal conflict. ${ }^{4}$ If single members' contributions to the collective good differ from what is considered appropriate, this upsets the other members. Donations will not be distributed and the resource wasteful regime emerges. Similarly, if all group members make adequate contributions to group output, but the big man's donations differ from what is considered adequate, then the organization will also end up in a wasteful conflict. Intuitively, anticipation of the wasteful regime as the consequence of neglecting one's own collective action duties or of inadequate donations may give each member of the organization an incentive to choose the adequate collective action and the 'big man' to make adequate donations. The fear of possible fighting and resource wasting conflict inside the organization can, hence, stabilize a fully efficient outcome in a static game.

\footnotetext{
${ }^{2}$ Orenstein et al. (1980: 71) also emphasizes the importance of material wealth as a key qualification for a 'big man' in this society.

${ }^{3}$ Such societies existed for long periods and in many regions. Leeson (2006) lists and categorizes a considerable number of such primitive societies and provides references that describe them.

${ }^{4}$ Our theory and in particular use of the term "norm" follows Hardin's influential view, that "an important fact about many norms is that behaviors they guide may be strongly reinforced by incentives of self-interest" (Hardin 1995: 22), which makes norms the subject of consequentialist analysis. This view is in stark contrast to, e.g., Elster, who claims that norms are not outcome-oriented (Elster 1989). In our non-cooperative game set-up behavior according to a norm gets reinforced by individual self-interest, while at the same time it is in the self-interest of any individual to have a (group) norm. Hardin 's further, more concrete observation that "many norms appear to have the strategic structure of coordination" (Hardin 1995: 73) also pertains to our model: the power of a group is greatly enhanced by the efficient coordination of individual efforts, which is achieved through the role of a clan leader, who also has (an incentive) to submit to the norm.
} 
Our analysis has several distinctive features. First, we do not rely on an infinitely repeated game framework, in which an efficient equilibrium results from purely strategy-induced dynamics. ${ }^{5}$

Second, all members of the group receive some-not necessarily the same-share in the group's income in the equilibrium. This share can be seen as a compensation for the member's contribution to collective action, but is not part of a formal contract. It is paid in a way that does not involve any promise or commitment by the recipient and is not motivated by other-regarding preferences or a desire for reciprocating. Third, group size is meaningful. Larger groups are more effective in generating group income. However, the clan's per-capita payoff is typically maximized for an intermediate clan size. Finally, the framework offers an explanation for why some organizations, clans, groups, or primitive states perform very well whereas others perform very badly. The analysis provides an example of the functioning, importance and implicit enforcement of norms: the implementation of the efficient collective action requires all players to have a common view about their appropriate contribution to the collective good and about what would be an appropriate or equitable distribution of rents. Compliance with this norm is reinforced by self-interest. Deviation from this norms by a single player would induce a shift from one equilibrium to another, less attractive one in a later stage. Hence the alignment of the norm with individual self-interest works twofold: self-interest is instrumental in stabilizing the norm, and the norm is instrumental in asserting self-interest.

\section{Related literature}

We distinguish several lines of literature that are strongly related to our analysis. First, the questions we address are related to the oldest and most fundamental questions that can be traced back to theories of early constitutional philosophers about anarchy, the power of coercion and the origin of property rights and the state. It is impossible to survey this literature here. A recent survey that focuses on the role of public choice theory on understanding the economics of anarchy is by Powell and Stringham (2009), showing that there are multiple reasons why a stateless economy may, but need not perform reasonably well, and identify forces that may stabilize its status or transform it into different forms of governance. Skaperdas (1992), Hirshleifer (1988, 1995) and Grossman (1994) analyzed economic behavior in the absence of property rights, where players choose between production of consumable output and appropriation effort, which may consist of stealing, arming or guarding, implying considerable inefficiency. Their work stimulated a major research program. ${ }^{6}$ Considerable research effort has also been devoted to the origin of a state with its rules of enforcement that may overcome the inefficiencies that apply in anarchy. Leeson (2006) distinguishes two

\footnotetext{
${ }^{5}$ Although our threat of punishment through Nash equilibrium reversion is similar to the one employed in repeated games, it also works in institutional set-ups with high discount rates and finite time horizons. A key aspect that is emphasized in many works on cooperation in the absence of formal enforcement is repeated interaction. Tullock (1972) already emphasizes it as a facilitator of trade in the absence of formal enforcement. A further example of spontaneous economic order is the development of securities trading in Amsterdam. Stringham (2003) analyses this phenomenon and highlights the importance of reputation and repeated interaction. Benson (1989) discusses several key aspects that were important for how and why commercial law could evolve as a spontaneous means to settle dispute. The importance of the option to terminate the (potentially fruitful) interaction is highlighted by Kurrild-Klitgaard (2002).

${ }^{6}$ See, for instance, Garfinkel and Skaperdas (2007) for an overview.
} 
types of theories in this context: social contract theories that build on the consensus of players and explore the role of a commitment technology ${ }^{7}$ and predatory theories in which a player with considerable enforcement power implements cooperation. ${ }^{8}$ The comprehensive survey by Powell and Stringham (2009) emphasizes that in many of these theories repeated interaction is a key aspect that stabilizes a cooperative or conflictless outcome. Our approach shows that internally peaceful and fully efficient group behavior can be the equilibrium outcome of a fully non-cooperative non-repeated game. We do not resort to a collective decision which provides this enforcement nor to an ultimate provider of enforcement with formal enforcement technologies. We show that collectively efficient and peaceful behavior within a group, organization or clan nevertheless can emerge. Conflict itself becomes the key driver in this process as the absence of enforcement institutions leads to a multiplicity of equilibria, some of which involve costly conflict and some of which do not. The norm allows the distribution of a "peace dividend" in an equilibrium without conflict, which emerges from efficient collective action and from abstention from fighting. A "bad" equilibrium is selected if players do not behave according to the norms.

Second, gift giving and gift exchange have been documented for a number of stateless societies and their instrumental role for explaining cooperative behavior or contract enforcement has been carefully studied (see, e.g., Landa 1994). Perhaps the most commonly known reciprocal gift-giving system is the 'potlatch' among the Southern Kwakiutl Indians. In this system economically successful players celebrated big feasts in which they transferred considerable resources to other players as gifts. Johnsen (1986) interprets this system and the status norms it is based on as means of reducing violent conflict between tribes and for al-

\footnotetext{
${ }^{7}$ Only a few recent examples are given here: De Meza and Gould (1992) consider a framework in which each player decides on whether to enforce property rights using his own resources. Private enforcement causes externalities. They study the implications of these externalities for equilibrium and welfare. Falkinger (2006) considers the non-cooperative investment in a punishment mechanism that enforces contracts. Sánchez-Pagés and Straub (2006) explain the endogenous emergence of norm enforcement institutions by agents' voluntary costly contributions to their formation. An enforcement technology is given, but players must still agree to adopt and use it. Once this decision is made and the enforcer of property rights is appointed, he uses this power benevolently and does not opportunistically abuse this power. Fearon (2008) suggests democratic elections as a device for collectively governing the governor: the group of players may give the power to enforce property rights when he interacts with single individuals. The group may, however, retain the ability to replace the ruler if it can coordinate on collective action (for instance, a revolution). Democratic elections, and whether they take place as they should and in an orderly fashion, are used as a coordination device for whether the ruler should be kept in power, or whether it is time for a collective action to replace the ruler. Gradstein (2007) analyses the relationship between income distribution, democratic choice of property rights regimes and growth performance. A majority decision enforces the property rights regime in his framework. Unanimous or majoritarian adoption of institutions has strong intuitive appeal. However, we would like to go one step further and provide an explanation for collectively efficient behavior which is self-enforcing in a fully non-cooperative equilibrium. Leeson (2008) emphasizes the adoption of desirable trading partners' behavioral or religious practices and gift-giving as ways to establish cooperation in contexts of repeated interaction in some African societies.
}

${ }^{8}$ Olson (1993) and McGuire and Olson (1996) analyzed the welfare outcome if a king or sovereign ruler has access to a power monopoly and can enforce property rights. A power monopoly may improve upon the situation with anarchy, provided that the ruler can commit himself to abstain from ex-post opportunistic behavior. Long-term considerations and the forces of infinitely repeated play may, but need not overcome what several writers identified as the fundamental problem with an agent who has the power to enforce property rights: his ability to abuse this very power and to extort his subjects even more severely than in a state of anarchy. See, for instance, Barzel (2000, 2002), Acemoglu et al. (2004), Myerson (2008) and Shen (2007), who also reviews this literature. Moreover, a competition for the position of enforcer of property rights may become an additional source of inefficiency and worsen the outcome compared to anarchy (Skaperdas 2002). Leeson (2007b) describes and analyses the historical institutions by which pirates avoided being subject to predation by their captain. 
lowing efficient management of a renewable resource, essentially preventing the group from overfishing. A second example comes from the trade relationships in late precolonial times between stationary producers in the interior of Central Africa and traders that visited the producer sites in caravans. Leeson (2007a) argues that the transfer of resources in advance from the trader to the producer that was very common in these relationships was a means of overcoming a hold-up problem. In the absence of credit, the traders would be inclined to use their power to plunder, rather than compensate the producers adequately, which, in turn, would induce the producers to minimize the production that could be taken from them. An upfront transfer of resources (credit) from the trader to the producer can solve the holdup problem. Our analysis follows similar lines. Our theory relies on the existence of a key player whose gift giving is instrumental for coordination on an efficient equilibrium.

A third line of related research studies voluntary contributions to collective goods. This research identified at least four different motivations for making own contributions. A contributor may benefit from an increase in the amount of the public good that is provided. ${ }^{9}$ A contributor may like the feeling of doing something good; Andreoni (1990) referred to this motivation as the warm glow of giving. Contributions to the public good may be instrumental for reaching other goals; Bagwell and Bernheim (1996) and Glazer and Konrad (1996) suggested that observably contributing to a public good may convey information to others and this may generate other benefits. Finally, Bénabou and Tirole (2006) introduced the role of self-image as a possible motivation for charitable giving. In our framework another motivation emerges: if individual contributions do conform with social norms, the non-cooperative outcome is peaceful. Otherwise societal conflict is induced and makes all players worse off. Hence individual contributions to group effort occur "in the shadow of conflict" (Hirshleifer 1994). Hirshleifer advances the much more general and provocative proposition that "cooperation, with a few obvious exceptions, occurs only in the shadow of conflict".

Our analysis is also related to research on the relationship between inter-group conflict and rules that govern the behavior of members of the same group vis-a-vis each other. Nitzan (1991) and Davis and Reilly (1999) consider the implications of different rules governing a peaceful distribution of resources inside the group for the willingness of group members to make voluntary contributions to group effort. These rules and the peaceful distribution inside the group are taken as exogenously given in these frameworks. Their work shows that merit rules, if they can be enforced, can supply important incentives for controlling free-riding. Katz and Tokatlidu (1996), Wärneryd (1998) and Müller and Wärneryd (2001) highlight that peaceful allocation rules inside the group cannot be taken for granted. A peaceful merit rule may be a desirable incentive system from the group's perspective, but in many contexts such rules cannot be enforced. In this case hierarchies of conflict may emerge, with a conflict between groups being followed by a conflict among the members of the victorious group for the prize. ${ }^{10}$ We as well consider an inter-group contest with possible free-riding of group members, that is followed by a strong intra-group contest about the allocation of the winner's prize. However, we show that these two activities may "incentivize" players mutually; efficient contributions to group effort and peaceful settlement of internal conflict may then be complementary equilibrium outcomes.

\footnotetext{
${ }^{9}$ See, e.g., McGuire (1974), Hirshleifer (1983), Cornes (1993) and Bergstrom et al. (1986) for seminal contributions in this formal context.

${ }^{10}$ This structure has been studied further by Glazer (2002) who discusses the cost and benefit of group members who are highly efficient fighters. They benefit the group in the conflict with rival groups, but they also appropriate a larger share in whatever the group wins.
} 
In political science there has been careful discussion about whether, and how, violent conflict can or cannot be avoided in the context of the theory of rational approaches to studying war. From this literature it turns out (see, e.g., Fearon 1995) that asymmetric information and commitment problems are the keys to explaining why conflict may take place, despite its obvious inefficiency compared to a peaceful settlement. However, Slantchev (2003) explains how the occurrence of multiple equilibria and differences in the desirability of reaching a particular equilibrium, together with expectations about what action triggers which equilibrium may lead to actual conflict. Conceptually, Slantchev's analysis is close to ours. Slantchev uses the framework of multiple equilibria to explain why wasteful conflict may emerge in a complete information world with non-cooperative bargaining. We use it to explain how (by using the conflict equilibria as credible threats) efficient cooperation and distributional harmony inside a group may emerge.

\section{Inside the clan}

Consider a clan that has $n$ members who constitute the set $N$. This clan owns some income $V=1$. The allocation of this income among its members is governed by an appropriation game in which contest efforts decide about the allocation of the prize, and in which the timing of the choices of contest efforts is endogenous. Prior to this appropriation game, in a first stage, G1, one designated player 1 is allowed to distribute non-negative payments $\left(a_{2}, a_{3}, \ldots a_{n}\right)$ to the other group members. We denote

$$
\mathbf{a} \equiv\left(a_{2}, a_{3}, \ldots a_{n}\right) \quad \text { and } \quad a \equiv \sum_{j=2}^{n} a_{j} .
$$

This player owns sufficient resources to make these payments, where $a_{j} \in[0, V]$ can be assumed without restricting generality; in fact $a$, the total amount this player transfers to the other players, can be restricted to be less than $V$. We call player 1 the big man. (Later in this section we will show, that this has to be the strongest member of the clan, i.e., he may be viewed as the first claimant of the clans's income $V$, who has to defend it in a contest against the other clan members unless he redistributes it appropriately.) Payments are fully unconditional in the following sense: members who receive a payment do not, and cannot, promise anything in exchange for the payment, and simply follow their own narrow interests in subsequent decision making. These payments also do not alter the set of possible actions to be taken by any clan member in the future. For simplicity, we assume that these payments are public information; all payments are observed by all members. ${ }^{11}$ Note, however, that payments can change the behavior of a player who is indifferent about his own future actions, or change players' expectations if there are multiple equilibria in the continuation game. The payments may therefore drive the selection between a peaceful equilibrium and violent fights inside the clan.

Stages G2-G4 describe the allocation of the prize in an all-pay auction with endogenous timing, building on Baik and Shogren (1992), Baik (1994, 2005) and Leininger (1993). The cornerstone of this allocation rule is a contest success function that maps clan members'

\footnotetext{
${ }^{11}$ This is mainly to be able to continue with a game with complete information. For the sake of the argument, it would be sufficient if each clan member observed his own $a_{j}$.
} 
effort choices into win probabilities. ${ }^{12}$ Let clan member $i$ choose effort $x_{i}$. The probability $p_{i}$ that $i$ wins the conflict is a function of all contestants' efforts,

$$
p_{i}=p_{i}\left(x_{1}, x_{2}, \ldots x_{n}\right) .
$$

Denote $\bar{x} \equiv \max _{k \in N}\left\{x_{k}\right\}$. If $x_{i}=\bar{x}>x_{j}$ for all $j \in N-\{i\}$, then $p_{i}=1$ and $p_{j}=0$ for all $j \neq i$. If there are several players who have chosen the same, highest effort, $\bar{x}$, we assume a tie-breaking rule that is outlined later. The three stages of this appropriation conflict game are as follows.

First, in stage G2, each member decides about the timing of his own choice of contest effort. There are two different points in time, early $(e)$ and late $(l)$. Each clan member must decide whether to make his effort choice at one of these points of time. If he chooses $e$, he cannot reduce or increase his effort choice at a later point in time $l$. Hence, clan members who choose $e$ give members who choose $l$ the opportunity to react to their effort choices. This formal modeling simply means, that any clan member can make a strategic precommitment to the level of effort. This may take the form of a directly imposed order of moves or occur indirectly through some other variable that will influence the ex post capacity to expend effort. Members who precommit are modelled as choosing $e$; they become Stackelberg leaders with respect to all who keep their options open and choose $l .^{13}$

In stage $\mathrm{G} 3$, the point in time $e$ is reached. At this point all observe their own and others' choices of timing. ${ }^{14}$ Anyone who decided to make his effort choice at $e$ chooses his $x_{i}$ simultaneously with all others who made this same timing decision. Effort cost is quadratic in effort, and we denote $i$ 's cost as

$$
C_{i}\left(x_{i}\right)=c_{i} x_{i}^{2}
$$

Clan members can, but need not, be symmetric. Generally we will assume that they may differ with respect to their cost of generating contest effort, and consider them sorted and numbered such that $c_{1} \leq c_{2} \leq \cdots \leq c_{n}$. Note that this together with the description of stage G1 implies that the big man has the lowest cost of contest effort. ${ }^{15}$

In stage $\mathrm{G} 4$, the point of time $l$ is reached. All observe the effort choices made by clan members who made this choice at time $e$. All others now decide simultaneously about their

\footnotetext{
${ }^{12}$ This contest success function is widely used. Alcalde and Dahm (2010) showed that this function is payoff equivalent to a very broad class of contest success functions.

${ }^{13}$ To illustrate, consider a clan which receives some amount of outside income which is contested among clan members, but in which each clan member also owns and tills his own piece of land. Let each clan member have two units of time, say, two months, before the winter season starts. He needs one month for tilling the ground, leaving him at most one month's time to engage in intra-group conflict. A clan member who does not till his ground in the first month will need to do this in the second month, as otherwise he sacrifices one year's return on his land. So he is committed not to spend any time and effort on contesting in the second month. Accordingly, a clan member who uses the entire first month for tilling the ground, has maximal capacity to expend contest effort, as he can choose how much of the second month to spend on contesting the clan's income. Hence, a clan member can precommit to any effort level or time spent in the contest by letting quietly pass a respective amount of time of the first month before he starts tilling his land.

${ }^{14}$ Note that this assumption is not needed. For the results in Proposition 1 to hold it is necessary only that the choice of $e$ or $l$ becomes common knowledge among all clan members prior to $l$, which is consistent with the idea that a choice of $e$ essentially means that a player delays mandatory duties to the future, and hence, commits to not using this future time for producing contest effort.

${ }^{15}$ Our results can be generalized to cost functions other than (3), but we constrain the analysis to this parametric case because it yields simple closed form solutions and allows for a simple ordering in terms of group members' effort costs.
} 
own efforts. The cost of a given amount of effort is the same whether chosen at $e$ or at $l$ and is described by the quadratic cost function (3). Recall that members who chose time $e$ cannot revise their effort choices at time $l$. Once all effort choices are made, the prize is allocated according to the contest success function (2).

For situations in which several clan members expend the same effort we adopt tiebreaking rules which are discussed at length in Konrad and Leininger (2007). The following lemma describes the equilibrium of the subgame starting in stage G3.

Lemma 1 The subgame starting at stage G3 has unique equilibrium payoffs for any given choices $t_{j} \in\{e, l\}$. Payoffs are characterized as follows:

$$
\pi_{j}=a_{j}, \text { for all } j=2, \ldots n,
$$

and

$$
\pi_{1}=\left\{\begin{array}{lc}
1-\sum_{j=2}^{n} a_{j} & \text { if } t_{1}=l \text { and } t_{j}=e \text { for all } j=2, \ldots n \\
1-\frac{c_{1}}{c_{j_{\min }}}-\sum_{j=2}^{n} a_{j} & \text { if } t_{1}=l \text { and } t_{j}=l \text { for some } j=2, \ldots n \\
& \text { with } c_{j_{\min }} \equiv \min \left\{c_{j} \mid t_{j}=l, j \neq 1\right\} \\
1-\frac{c_{1}}{c_{2}}-\sum_{j=2}^{n} a_{j} & \text { if } t_{1}=e .
\end{array}\right.
$$

The result is proven in Konrad and Leininger (2007), who combine and extend results of Baye et al. (1996) and Kaplan et al. (2003). Intuitively, if $t_{1}=l$ and $t_{j}=e$ for all $j=2, \ldots n$, then it makes no sense for $j$ to expend positive effort, as any effort that costs $j$ less than the value of the prize will be overbid by player 1 in the last round. Player 1 wins without any significant effort and his payoff equals the value of the prize, minus his unconditional payments from stage G1. Moreover, players $2, \ldots n$ receive nothing but the unconditional payment $a_{j}$. This explains the first line in (5). A similar argument applies whenever player 1 chooses $t_{1}=l$. All players who choose $t_{j}=e$ will not spend positive effort, because they cannot win a positive payoff by any positive effort choice. However, player 1 will be in a contest with other players who also chose $t_{j}=l$. Given $x_{j}=0$ by all players who choose $t_{j}=e$, the contest essentially reduces to a simultaneous contest among the group of players $k$ who chose $t_{k}=l$. The equilibrium outcome of this simultaneous contest is well known. Only the two players with the lowest cost parameter bid positive effort, which are player 1 and player $j_{\min }$. The equilibrium is in mixed strategies, and some of the prize will be dissipated. For quadratic cost, $\frac{c_{1}}{c_{\min }}$ is the share that is dissipated. Finally, if player 1 chooses $t_{1}=e$, one can distinguish two cases. If $j=2$ chooses $t_{j}=l$, then player 1 with the lowest cost can pre-empt player 2 by a sufficiently high bid $x_{1}=\frac{1}{\sqrt{c_{2}}}$, which just yields the payoff $\left(1-\frac{c_{1}}{c_{2}}\right)$. If, instead, $j=2$ chooses $t_{j}=e$, then things are more complicated and the equilibrium strategies take into account that players with $t_{k}=l$ may overbid low effort levels, but the same intuition goes through: $j=2$ is the main competitor for player 1 and induces a dissipation equal to $\frac{c_{1}}{c_{2}}$. In particular, $j=1$ can always attain at least $\left(1-\frac{c_{1}}{c_{2}}\right)$ by a choice $x_{1}=1 / \sqrt{c_{2}}$, as no other player will ever reasonably choose a higher effort. This limits his payoff from below, and, with some formal analysis, one can also show that this also limits his effort from above (see Konrad and Leininger 2007). The bidding of players at stage $l$ can be interpreted as an all-pay auction with a minimal bid requirement (namely, submit a bid at least as high as the highest bid from stage $e$ ). Perhaps surprisingly, bidding in the first stage 
$l$ also reduces to an all-pay auction with a minimal bid requirement (namely, submit a bid at least as high as the highest individually rational bid of the player with the least cost, who moves at $l$ ).

Note that all players $j=2, \ldots n$ are fully indifferent with respect to their choice of timing. Their overall payoff is equal to the unconditional payment $a_{j}$, and their payoff from participating in the contest is zero in expectation and independent of their timing. Their choices matter for player 1's payoff, and if he could influence their behavior, he would have a strictly positive willingness to pay for making them choose $t_{j}=e$.

Consider now stage G2.

Lemma 2 For player 1 the choice of $t_{1}=l$ is a weakly dominant decision in the following sense:

(i) For any timing decisions $t_{-1}=\left(t_{2}, \ldots, t_{n}\right)$ by players 2 to $n$ there is a subgame perfect equilibrium of the full game with $t^{*}=\left(l, t_{2}, \ldots, t_{n}\right)$

(ii) For any $t_{-1}=\left(e, t_{3}, \ldots, t_{n}\right)$ the decision $t_{1}=l$ is the unique equilibrium choice of player 1 .

The proof of Lemma 2 follows from Proposition 2 in Konrad and Leininger (2007).

Lemma 1 and Lemma 2 together suggest that the continuation game consisting of stages G2-G4 has at least $2^{n-1}$ equilibria. In each of these equilibria player 1 chooses $t_{1}=l$, but this choice can go along with any combination $\left(t_{2}, \ldots, t_{n}\right)$ by the other players. The payoff for player $j$, with $j \in\{2, \ldots, n\}$, is $a_{j}$ for all equilibria. The payoff for player 1 is highest and equal to $1-\sum_{j=2}^{n} a_{j}$, if $\left(t_{2}, \ldots, t_{n}\right)=(e, \ldots, e)$, and lowest and equal to $1-\frac{c_{1}}{c_{2}}-\sum_{j=2}^{n} a_{j}$, if $\left(t_{2}, \ldots, t_{n}\right)=\left(l, t_{3}, \ldots, t_{n}\right)$. Note, that player 1 is indifferent between $t_{1}=e$ and $t_{1}=l$ if $t_{2}=l$; hence there are also equilibria in which player 1 chooses $e$, but these do not lead to new equilibrium payoff vectors.

In contrast, each of the players $j=2, \ldots n$ is fully indifferent with respect to his own choice of timing and the choice of timing by all other players. The choice of timing $t_{j}$ can therefore depend on any event or action that is observable at the beginning of G2; for instance on the payments made to group members. We denote this relationship as

$$
t_{j}=\tau_{j}\left(a_{2}, a_{3}, \ldots a_{n}\right) .
$$

This directly leads to

Proposition 1 Define $\mathcal{A} \equiv\left\{\left(a_{2}, \ldots a_{n}\right) \mid a<\frac{c_{1}}{c_{2}}\right.$ and $a_{j} \geq 0$ for $\left.j=2, \ldots n\right\}$. Then, for any $\mathbf{a} \in \mathcal{A}$, there exists a subgame perfect equilibrium of the game, in which player 1 chooses $\mathbf{a}$ at the first stage.

Proof Let $t_{1} \equiv l$, but

$$
\tau_{j}(a)= \begin{cases}e & \text { if } \mathbf{a}=\mathbf{a}^{*} \\ l & \text { if } \mathbf{a} \neq \mathbf{a}^{*} .\end{cases}
$$

By Lemmas 1 and 2, this behavior yields $\pi_{j}=a_{j}$ for all $j=2, \ldots n$ in the subgame perfect equilibrium, independent of $j^{\prime} s$ choice of timing, and payoff $\pi_{1}=1-a^{*}$ if $\mathbf{a}=\mathbf{a}^{*}$ and $\pi_{1}=1-\frac{c_{1}}{c_{2}}-a$ otherwise. Player 1 maximizes his payoff by $\mathbf{a}=\mathbf{a}^{*}$ if $a^{*} \leq \frac{c_{1}}{c_{2}}$, and by $\mathbf{a}=(0,0, \ldots 0)$ if $a^{*}>\frac{c_{1}}{c_{2}}$. 
Groups may overcome the problem of wasteful internal fights about the distribution of the group income between its members in a fully non-cooperative game without repeated interaction, without reputation building, and without relying on the rules of a non-cooperative bargaining game. This peaceful equilibrium is compatible with a large number of distributions of the group income. The big man receives at least what he could obtain from fighting, and any division of the 'peace dividend' $\frac{c_{1}}{c_{2}}$ is compatible with Proposition $1 .^{16}$

Note that Proposition 1 implicitly assumed that the role as big man was assigned to the player who is the strongest fighter, as $c_{1}=\min _{j \in N}\left\{c_{j}\right\}$. A player $j$ with $c_{j}>c_{1}$ cannot be the big man. If he were to make positive transfers $a>0$, he could never retrieve them. His payoff from the intra-group contest in any equilibrium would be 0 . Hence any sort of competition for the role of big man would see player 1 prevail. The sequencing of timing decisions has two effects: it not only yields equilibria in pure strategies, but also an "efficiency gain" if players move in an appropriate order. The latter effect relies on the possibility that the strongest player can use his advantage against weaker players through their expectations (i.e. without having to exert it) if he moves late (and the others early). If he moves early (or others join him in moving late), he actually has to exert his greater strength by making the largest effort bid. This seriously limits the potential of any player other than the strongest of becoming the big man.

\section{Collective action}

One of the quintessential public goods problems in the context of primitive societies is the collective provision of effort to defend the clan's territory, or to expand this territory at the expense of rivals or enemies. The formation of clans, groups or states facilitates the provision of collective goods. ${ }^{17}$ Returns to scale, or the importance of country size for relative strength in international conflict, has been one of the key drivers of a process of consolidation and the formation of ever larger units. ${ }^{18}$

The 'external' conflict. Consider the competition between the clan and an enemy for a prize that can again be seen as an amount of resources, e.g., money or some homogenous universal good that is valued at $V=1$. The contest follows the rules of an all-pay auction similar to the rules of the possible intra-clan conflict. Let $y_{E}$ be the total contest effort chosen by the enemy, and the enemy's cost of providing this effort

$$
D_{E}\left(y_{E}\right)=c_{E} y_{E}^{2} \text {. }
$$

\footnotetext{
${ }^{16}$ This indeterminacy is not uncommon, of course, in other contexts, e.g., the cake-eating problem. The main difference is that we do not make any assumption about procedural rules that the players agree to, and explicitly allow for resource wasteful appropriation effort here.

${ }^{17}$ The provision of fundamental public goods such as internal and external security is clearly a fundamental problem under anarchy. A large share of the literature considers the origin of the state as a type of business model: players with coercive power settle and become what is called "stationary bandits": they ruled over people and extract rents from them (see, e.g., Oppenheimer 1908; Holcombe 2004). Eventually they improve this business concept by providing public goods.

${ }^{18}$ Riker (1966, pp. 2-3, 8-9) emphasizes military considerations as central for the formation of federations, and illustrates this using examples starting from the federation of city states in Ancient Greece. The theory of the optimal size of nations by Spolaore and Alesina (2002) attributes the recent breakup of larger nation states to the decline in the importance of international military conflict in most modern, post cold-war times.
} 
Further, let each clan member decide on his own contribution $y_{j}$ to the clan's effort, which causes a cost of effort to this member that is equal to ${ }^{19}$

$$
D_{j}\left(y_{j}\right)=c_{j} y_{j}^{2}
$$

Let the external conflict efforts sum up to the total effort:

$$
y_{C}=\sum_{j=1}^{n} y_{j} .
$$

This simple form of aggregating individual efforts is frequently assumed in the literature on private provision of public goods. ${ }^{20}$ Our mechanism for implementing efficient contributions can easily be adapted to a whole class of other functions. ${ }^{21}$

The contest between the clan and the enemy is again governed by the same type of contest success function: the clan or the enemy wins the prize, depending on who expends higher effort. A fair coin decides who wins the prize if $y_{C}=y_{E}$.

From the perspective of member $i$, any contribution $y_{i}$ to the aggregate level of $y_{C}$ is a contribution to a clan-wide pure public good. We first determine what the combinations of effort $\left(y_{1}, \ldots y_{n}\right)$ are that are collectively optimal from the perspective of the clan. Then we show that this collectively optimal behavior can be implemented as a fully non-cooperative equilibrium, taking into consideration that the prize must be allocated among the clan members if the clan wins the prize, and that this involves some intra-clan conflict as studied in the previous section.

Optimal collective effort in the inter-group conflict. Suppose that the clan manages to coordinate on a peaceful equilibrium once it wins the prize. In this case, the clan collectively values the prize by its nominal value, which we normalized to $V=1$. The optimal choice of the clan's effort $y_{C}$ will generally depend on the enemy's choice of effort. However, the following proposition determines how a given amount of aggregate effort can be generated in an effort cost minimizing way.

Proposition 2 If the clan generates a given amount of aggregate effort $y$ in a cost minimizing way, the clan's aggregate effort cost is equal to

$$
D_{C}(y)=c y^{2} \quad \text { with } c \equiv \frac{1}{\sum_{j=1}^{n} \frac{1}{c_{j}}} .
$$

\footnotetext{
${ }^{19}$ The use of the same $c_{j}$ in (3) and (9) is mainly for notational parsimony. Clan members may differ in their relative abilities for internal and external fights, but often these abilities should be expected to be positively correlated.

${ }^{20}$ McGuire (1974) introduced this setup when studying collective action. The seminal paper using this technology is Bergstrom et al. (1986). For the case with contribution substitutability but convex individual contribution cost see Esteban and Ray (2001). For further discussion and a survey see Batina and Ihori (2005).

${ }^{21}$ Other technologies are Hirshleifer's (1983) "weakest link" model with $y_{C}=\min \left(y_{1}, \ldots, y_{n}\right)$, or the "best shot" model with $y_{C}=\max \left(y_{1}, \ldots, y_{n}\right)$, or the case of a discontinuous public good such that the public good is provided if and only if the sum of contributions exceeds a given threshold as in Bagnoli and Lipman (1989). In some of these cases an efficient non-cooperative outcome exists already if there is no threat of an intra-group conflict.
} 
Proof The cost function $D_{C}(y)$ of the clan is obtained as the solution to the maximization problem $y_{C}=y_{1}+y_{2}+\cdots+y_{n} \rightarrow \max$ subject to $\sum_{j=1}^{n} c_{j} y_{j}^{2} \leq D$. The solution requires

$$
D_{C}^{\prime}(y)=2 c_{i} y_{i}^{*}(y) \quad \text { for all } i=1, \ldots n .
$$

Accordingly, $y_{i}^{*}(y)=\frac{D_{C}^{\prime}(y)}{2 c_{i}}$, and $y=\sum_{j=1}^{n} \frac{D_{C}^{\prime}(y)}{2 c_{j}}$. This, in turn, implies

$$
D_{C}^{\prime}(y)=\frac{y}{\sum_{j=1}^{n} \frac{1}{2 c_{j}}} .
$$

Integrating and taking into consideration that $D_{C}(0)=0$ yields $(11)$.

Note that $c$ as defined in (11) decreases if the clan grows by an additional member. This monotonicity holds whatever are the current size of the clan and the combination of cost parameters. Large clans have a lower cost of a given amount of effort in an external conflict if this amount of effort is efficiently provided: if there are more clan members, each member needs to contribute a smaller portion of the given clan effort, and, with increasing marginal cost, the aggregate cost is decreasing in the number of clan members.

Also note that the cost parameter $c$ of the clan cost function $D_{C}(y)$ equals $\frac{1}{n}$ times the harmonic mean $h\left(c_{1}, \ldots, c_{n}\right)$ of the individual cost function parameters:

$$
c=\frac{h\left(c_{1}, \ldots, c_{n}\right)}{n} .
$$

Since $h\left(c_{1}, \ldots, c_{n}\right)>\min \left\{c_{1}, \ldots, c_{n}\right\}$ we conclude that

$$
\frac{1}{n} h\left(c_{1}, \ldots, c_{n}\right)<\min \left\{c_{1}, \ldots, c_{n}\right\}
$$

This is a technological source of feasible "efficiency gains" for the clan beyond the big man's strength. These gains increase in $n$ and the strength of any new member of the clan.

Proposition 2 means that clan member $j$ has to contribute effort $y_{j}^{*}(y)=\frac{c}{c_{j}} y^{2}$ at individual cost $\frac{c^{2}}{c_{j}} y$ in the efficient provision of clan effort $y$. That is, all members have to contribute and stronger members have to contribute more than weaker members.

The lower cost translates into an advantage in the external conflict with an enemy if the clan can manage to mobilize each member to contribute the efficient amount of effort. Let the clan maximize

$$
\pi_{C}(y)=F_{E}(y)-D_{C}(y)=\operatorname{Prob}\left(y_{E}<y\right)-D_{C}(y)
$$

and, similarly, the enemy maximize,

$$
\pi_{E}(y)=F_{C}(y)-D_{E}(y)=\operatorname{Prob}\left(y_{C}<y\right)-D_{E}(y) .
$$

Then the following holds:

Proposition 3 Consider the all-pay auction contest between the clan and an enemy for a prize which they both value at 1 . If the clan can choose its aggregate effort efficiently in order to maximize (14), the equilibrium payoff is

$$
\pi_{C}^{*}=\max \left\{1-\frac{c}{c_{E}}, 0\right\} .
$$


A proof relies on the standard result for an all-pay auction between two contestants with the same valuations and quadratic cost functions (8) and (11).

The proposition shows that the clan can win a positive expected payoff in the wasteful conflict with the enemy if

$$
c_{E}>c .
$$

This condition defines the potential superiority of the clan in the conflict with the enemy. As $c$ depends on the number and cost distribution of clan members, this superiority is endogenous with respect to the composition of the clan.

Equilibrium collective action. The external conflict takes place in a stage $\mathrm{W}$ (ar). As discussed above, if the clan and its enemy choose their efforts $y_{C}$ and $y_{E}$ in order to maximize their respective payoffs, the equilibrium is in mixed strategies in which the effort choices are drawn from random variables with cumulative density functions $F_{C}$ and $F_{E}$, respectively. Efficient provision of a given effort level $y_{C}$ by the clan requires a particular, unique allocation of efforts, $\left(y_{1}, \ldots, y_{n}\right)$, among its members. If $y_{C}$ is a draw from a random distribution, it is therefore important for efficiency that the individual effort choices and the choice of $y_{C}$ are perfectly correlated. In order to make this feasible, we allow for the following coordination device. Some number $\theta$ is chosen as the outcome of a random draw from a distribution with cumulative density

$$
F_{C}(\theta)= \begin{cases}0 & \text { for } \theta \leq 0 \\ c_{E} \theta^{2} & \text { for } \theta \in\left(0, \frac{1}{\sqrt{c_{E}}}\right) \\ 1 & \text { for } \theta \geq \frac{1}{\sqrt{c_{E}}} .\end{cases}
$$

This $\theta$ is observed by all clan members (but not by the enemy) before they freely and simultaneously make their individual effort choices $y_{j}$. Once all clan members and the enemy have chosen their efforts, $\theta$ and all effort choices are observed by all players. If the enemy wins, the game is over.

If the clan wins, then the clan members enter into stages G1-G4 as discussed in the section on internal conflict.

Proposition 4 Let the clan be potentially superior to the enemy in the sense of (17). If $c_{1}-c_{2}$ is sufficiently close to zero, then a subgame perfect equilibrium exists in which the clan can implement the externally efficient efforts and a peaceful distribution of rents from war.

Proof Lemma 1 and Lemma 2 characterize the equilibria of the subgames consisting of stages G2-G4. Each clan member except the big man is indifferent whether to choose $t_{j}=e$ or $t_{j}=l$. The choices and the equilibrium of G2-G4 can therefore depend on the history of the game at the beginning of G2. At G2, a history consists of a $\theta$, choices of efforts in the inter-group conflict by the clan members, $\left(y_{1}, \ldots, y_{n}\right)$, an effort choice by the enemy, $y_{E}$, an outcome of the contest in which the clan wins the prize, and a vector of transfers $\left(a_{2}, \ldots, a_{n}\right)$ that was chosen and paid by the big man in stage G1. Hence,

$$
t_{i}=\tau_{i}\left(\theta, y_{1}, \ldots y_{n}, y_{E}, a_{2}, \ldots, a_{n}\right)
$$

replaces (6). 
Consider the following candidate choice of timing in the continuation equilibrium at G2 as a function of the history up to this point,

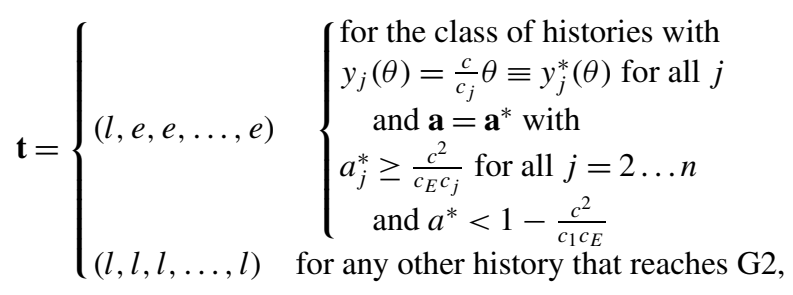

and the equilibrium payoffs determined by these choices as characterized in Proposition 1. To confirm that (20) can induce an efficient subgame-perfect equilibrium of the overall game, consider first $\mathrm{G} 1$ which is reached if the clan was victorious in the external conflict.

If at least one clan member deviated from $y_{j}^{*}(\theta)$, then $\mathbf{t}=(l, l, \ldots l)$, independent of $\mathbf{a}$. Accordingly, the big man chooses $\mathbf{a}=(0,0, \ldots, 0)$ in this case, and the payoffs in the subgame are

and

$$
1-\frac{c_{1}}{c_{2}}-c_{1} y_{1}^{2} \quad \text { for } j=1
$$

$$
-c_{j} y_{j}^{2} \text { for } j=2, \ldots n .
$$

If all clan members have chosen $y_{j}^{*}(\theta)$, the big man's choice of a determines the equilibrium outcome of the subgame in stages G2-G4. For $\mathbf{a} \neq \mathbf{a}^{*}$, the payoffs are

and

$$
\pi_{1}-c_{1}\left(y_{1}^{*}(\theta)\right)^{2}=1-\frac{c_{1}}{c_{2}}-a-c_{1}\left(y_{1}^{*}(\theta)\right)^{2}
$$

$$
\pi_{j}-c_{j}\left(y_{j}^{*}(\theta)\right)^{2}=a_{j}-c_{j}\left(y_{j}^{*}(\theta)\right)^{2} \text { for } j=2, \ldots n,
$$

and, among these transfer payments, the big man's payoff is maximal for $\mathbf{a}=(0,0, \ldots, 0)$. Alternatively, the big man can choose $\mathbf{a}=\mathbf{a}^{*}$. This yields payoffs

and

$$
1-a^{*}-c_{1}\left(y_{1}^{*}(\theta)\right)^{2} \text { for } j=1
$$

$$
a_{j}^{*}-c_{j}\left(y_{j}^{*}(\theta)\right)^{2} \text { for } j=2, \ldots n \text {. }
$$

The big man chooses $\mathbf{a}^{*}$ if

$$
\frac{c_{1}}{c_{2}}-a^{*} \geq 0
$$

Note that $a^{*}<1-\frac{c^{2}}{c_{1} c_{E}}$ in (20) and (24) are simultaneously fulfilled for potential superiority if $c_{1} / c_{2}$ is sufficiently close to 1 and hence $c_{1}-c_{2}$ small.

Turn now to the stage $\mathrm{W}$. The mixed strategy described by the cumulative density function

$$
F_{E}^{*}\left(y_{E}\right)=\left(1-\frac{c}{c_{E}}\right)+c y_{E}^{2} \quad \text { for } y_{E} \in\left[0, \frac{1}{\sqrt{c_{E}}}\right)
$$

is the enemy's optimal reply to $F_{C}^{*}(y)=F(\theta)$ as any $y_{E} \in\left[0, \frac{1}{\sqrt{c_{E}}}\right)$ yields the enemy an expected payoff of zero and higher effort $y_{E}$ yields negative expected payoff. 
Taking $F_{E}^{*}$ and the equilibrium effort choices $y_{k}^{*}(\theta)$ of all other clan members $k \neq j$ as given, $j \neq 1$ chooses between $y_{j}^{*}(\theta)$ which yields payoff

$$
-c_{j}\left(y_{j}^{*}(\theta)\right)^{2}+F_{E}(\theta) a_{j}^{*},
$$

and $\arg \max _{y_{j} \neq y_{j}^{*}(\theta)}\left\{-c_{j}\left(y_{j}\right)^{2}\right\}=0$. The latter makes use of $a_{j}=0$ if $y_{j}(\theta) \neq y_{j}^{*}(\theta)$, and of $j$ 's payoff from the actual intra-clan conflict being zero for $j \neq 1$. The two possible candidates for an optimum are $y_{j}=0$ or $y_{j}=y_{j}^{*}(\theta)$. Investment level $y_{j}^{*}(\theta)$ is chosen if $-c_{j}\left(y_{j}^{*}(\theta)\right)^{2}+F_{E}(\theta) a_{j}^{*}>0$. This is the case if

$$
a_{j}^{*}>\frac{c_{j}\left(\frac{c}{c_{j}} \theta\right)^{2}}{\left(1-\frac{c}{c_{E}}+c \theta^{2}\right)}
$$

for $j=2, \ldots, n$. As the right-hand side of (27) is increasing in $\theta$, condition (27) is strongest for $\theta=\frac{1}{\sqrt{c_{E}}}$, for which it becomes

$$
a_{j}^{*}>\frac{c^{2}}{c_{E} c_{j}} .
$$

Taking $F_{E}^{*}$ and the equilibrium effort choices $y_{j}^{*}(\theta)$ of all $j \neq 1$ as given, $j=1$ chooses between $y_{1}^{*}(\theta)$, by which he attains a payoff

$$
-c_{1}\left(y_{1}^{*}(\theta)\right)^{2}+F_{E}^{*}(\theta)\left(1-a^{*}\right),
$$

which is his payoff in the efficient equilibrium in the intra-clan contest which results from a choice of $\mathbf{a}^{*}$, and the payoff from $y_{1} \neq y_{1}^{*}(\theta)$ that maximizes

$$
-c_{1} y_{1}^{2}+F_{E}^{*}\left(\theta-\left(y_{1}^{*}-y_{1}\right)\right)\left(1-\frac{c_{1}}{c_{2}}\right) \text {. }
$$

The characterization of the payoff (30) uses the fact that a deviation from $y_{1}^{*}(\theta)$ will induce $a=0$ and the equilibrium with violent intra-clan conflict. The choice problem of the big man therefore reduces to the choice between $y_{1}^{*}(\theta)=\frac{c}{c_{1}} \theta$ and $\arg \max _{y_{1} \neq y_{1}^{*}(\theta)}\left\{-c_{1} y_{1}^{2}+\right.$ $\left.\left(\left(1-\frac{c}{c_{E}}\right)+c\left(\theta-\frac{c}{c_{1}} \theta+y_{1}\right)^{2}\right)\left(1-\frac{c_{1}}{c_{2}}\right)\right\}$. Let $c_{2}-c_{1}=\delta$. The argument that maximizes (30) tends to $y_{1}=0$ as $\delta \rightarrow 0$, and player 1's maximized payoff converges towards zero as $\delta \rightarrow 0$. Accordingly, the candidate equilibrium effort $y_{1}=y_{1}^{*}(\theta)$ is chosen if $-c_{1}\left(y_{1}^{*}(\theta)\right)^{2}+F_{E}^{*}(\theta)\left(1-a^{*}\right)>0$. Inserting the equilibrium values $y_{1}^{*}(\theta)=\frac{c}{c_{1}} \theta$ and $F_{E}^{*}(\theta)=\left(1-\frac{c}{c_{E}}\right)+c \theta^{2}$ yields the condition

$$
1-a^{*}>\frac{\frac{c^{2}}{c_{1}} \theta^{2}}{\left(1-\frac{c}{c_{E}}+c \theta^{2}\right)}
$$

As $\frac{\frac{c^{2}}{c_{1}} \theta^{2}}{\left(1-\frac{c}{c_{E}}+c \theta^{2}\right)}$ is monotonically increasing in $\theta$, the condition (31) is strongest for $\theta=\frac{1}{\sqrt{c_{E}}}$, for which it becomes

$$
1-a^{*}>\frac{c^{2}}{c_{1} c_{E}}
$$


For the condition (32) to be compatible with the conditions (28), it must hold that

$$
1-\sum_{j=2}^{n} \frac{c^{2}}{c_{E} c_{j}}>\frac{c^{2}}{c_{E} c_{1}}
$$

or $1-\sum_{j=1}^{n} \frac{c^{2}}{c_{E} c_{j}}>0$, or $1-\frac{c c}{c_{E}} \sum_{j=1}^{n} \frac{1}{c_{j}}>0$, or, equivalently, $1-\frac{c}{c_{E}}>0$, which is identical with the condition of potential superiority.

Potential superiority of the clan is one prerequisite from the external conflict structure for sustainability of the efficient effort in equilibrium. Another prerequisite from the internal conflict structure is limited potential superiority of the big man inside the clan. A strong "deputy" player 2 of the big man 1 not only increases competitiveness in the external contest, but also poses a larger threat (see (30)) in the internal contest, which stabilizes the efficient equilibrium.

Also note that the incentive compatibility constraints (28) and (32) for an efficient equilibrium mean that any resource distribution $\left(1-a^{*}, a_{2}^{*}, \ldots, a_{n}^{*}\right)$ in such an equilibrium must award at least a share of $\frac{c}{c_{E}}$ of the resource in accordance with 'merit': the minimal individual requirements $\frac{c^{2}}{c_{E} c_{j}}, j=1, \ldots, n$, add up to $\frac{c}{c_{E}}$. Only a part of $\left(1-\frac{c}{c_{E}}\right)$ can be distributed otherwise. E.g. Nitzan (1991) in a different context of collective rent-seeking exogenously imposed "mixed sharing rules" of the form

$$
s_{i}\left(y_{1}, \ldots, y_{n}\right)=(1-t) \frac{1}{n}+t \frac{y_{i}}{\sum y_{j}} ;
$$

i.e. a share $t$ of the resource is distributed according to (relative) effort and the remaining part is distributed on egalitarian grands ( $s_{i}$ denotes player $i$ 's share). Our analysis shows that a peaceful efficient solution for the clan implicity (and endogenously) imposes $t>\frac{c}{c_{E}}$; in particular, if potential superiority is weak and hence $c$ close to $c_{E}$, there is little room for egalitarian considerations.

The case $c_{1}=c_{2}$ is an interesting benchmark case. The incentives to coordinate on the peaceful outcome are largest here; coordination is feasible at, and in the neighborhood of this benchmark case. Intuitively, at $c_{1}=c_{2}$, if coordination fails, the big man does not receive a positive payoff even if the clan wins the prize in the external conflict, and his incentives to pursue a "stand alone" strategy in which he cheats on effort in the external conflict, and then also does not make positive transfers, are minimal, because his payoff in the resulting fighting equilibrium is zero. The opposite benchmark case is obtained if $c_{1} \ll c_{2}$, and $c \approx c_{E}$. In this case the big man does not gain much from coordinated action, as the overall prize the clan wins from coordinated action is negligible. It turns out that the efficient coordinated equilibrium cannot be supported for all cost parameter values. ${ }^{22}$

\footnotetext{
${ }^{22}$ Assume, for instance, that $c_{E}=1+\epsilon$ and consider the limiting case with $\epsilon \rightarrow 0$. Assume further that $N=\{1,2,3\}$, with $c_{1}=2, c_{2}=c_{3}=4$. Note that $c=1$. Note further that the maximum effort by the enemy is $y_{E_{\max }}=1$, as $D_{E}(1)=1=V$. If the members of $N$ play efficiently, the maximum $\theta=1$ is generated by effort levels $y_{1}^{*}=\frac{c}{c_{1}} \theta=\frac{1}{2}$ and $y_{2}^{*}=y_{3}^{*}=\frac{1}{4}$. Hence, the minimum that needs to be paid to 2 and 3 is $a_{2}^{*}=a_{3}^{*}=c_{2}\left(y_{2}^{*}(1)\right)^{2}=4 \frac{1}{16}=\frac{1}{4}$. The big man ends up with a rent that equals $1-2\left(\frac{1}{2}\right)^{2}-2 a_{2}^{*}=$ $1-\frac{1}{2}-\frac{2}{4}=0$. Now consider a big man who defaults, given $\theta=1$, and chooses $y_{1}=0$. In this case, $N$ wins with a probability $F_{E}(1 / 2)=c\left(\frac{1}{2}\right)^{2}=1 / 4$, and, once the clan wins the prize, the big man receives an expected contest payoff in the intra-clan contest that equals $\left(1-\frac{c_{1}}{c_{2}}\right)=1 / 2$. Hence, the payoff is zero if the big man behaves according to the equilibrium candidate of Proposition 4 , but receives $1 / 8$ if he defaults.
} 
Proposition 4 characterizes rules for contributions to the collective action and transfers from the big man to the other clan members that serve as a norm. If all players obey the norm, the outcome is efficient from the perspective of the group. Moreover, all players have an incentive to obey the norm. The norm is also self-enforcing.

Many other norms can also be sustained as an equilibrium by the fact that the players can reach the peaceful equilibrium only if they obey the norm. These norms may support an equilibrium in which the behavior of the clan members is suboptimal from the clan perspective. An example would be to replace $y_{j}^{*}(\theta)=\frac{c}{c_{j}} \theta$ by some $y_{j}^{*}=\frac{c}{c_{j}} \theta+\delta$ for sufficiently small $\delta$. This choice makes the clan win the contest with probability 1 . It also causes some excessive effort cost. But, if $\delta$ is small, and if this behavior is a necessary condition for coordinating on the peaceful equilibrium, this inefficient norm can be sustained. This reproduces an important property of norms. Norms are excessively stable in the sense that they may become obsolete or inferior to some alternative norm but may still continue to be obeyed.

Finally, the distribution of cost functions inside the clan is important, but the number of clan members also matters. Consider, for instance, a given $c_{E}$ and a set of players who all have the same cost parameter $c_{0} \gg c_{E}$. As

$$
\lim _{n \rightarrow \infty} c(n) \equiv \lim _{n \rightarrow \infty} \frac{1}{\sum_{j=1}^{n} \frac{1}{c_{0}}}=0,
$$

a sufficiently large clan exists such that $c_{E}>c$, making the payoff of the clan in the peaceful non-cooperative equilibrium that is characterized in Proposition 4 strictly positive. ${ }^{23}$

\section{Conclusions}

Experience from everyday life tells us that if individual members of a group do not do their "duty", this can upset the peaceful regime that may otherwise prevail inside the group. If the norms about social behavior within the group are violated by some group members not contributing what is considered to be their appropriate share of contributions to the common interest, this may induce other members of the group to reconsider given predispositions of intra-group distribution of resources and may cause quarrelling among the group members. Such quarrelling dissipates resources and is collectively disadvantageous. In turn, anticipation of quarrelling as a consequence of neglecting own duties may give the group members an incentive to behave responsibly. Hence, the fear of possible fighting and resource wasting conflict inside the group may stabilize an efficient outcome in which group members voluntarily contribute to group specific public goods.

In this paper we provide a microeconomic underpinning for this everyday life experience within the strictly non-cooperative framework of a finite multi-stage game. Multiple equilibria can exist with respect to the distribution of resources within the group, some of which are peaceful and some of which are characterized by resource wasting conflict. If the selection of equilibrium is driven by the group members' conduct with respect to their contributions to a group specific public good, this can induce fully efficient voluntary contributions to the public good. Our result is derived in the context of stateless societies. It hence also constitutes a contribution to the economics of anarchy by showing that anarchy and efficiency are compatible.

\footnotetext{
${ }^{23}$ Note that (35) does not imply that maximum sized clans yield the highest per-capita payoffs for its members. The clan size that maximizes per-capita payoff is typically finite, given that the maximum clan income is finite.
} 
Acknowledgements We thank participants in workshops on Economic Theory at the Reisensburg, on Polarization and Conflict in Palma, on the Emergence of Institutions in Edinburgh and on Contests in Stockholm, Warwick and Nottingham for comments and discussion. We also thank our reviewers and our editor for the helpful comments and suggestions. The usual caveat applies. Konrad acknowledges financial support by the German Science Foundation (DFG SFB-TR 15).

Open Access This article is distributed under the terms of the Creative Commons Attribution Noncommercial License which permits any noncommercial use, distribution, and reproduction in any medium, provided the original author(s) and source are credited.

\section{References}

Acemoglu, D., Robinson, J. A., \& Verdier, T. (2004). Kleptocracy and divide-and-rule: a model of personal rule. Journal of the European Economic Association, 2(2-3), 162-192.

Alcalde, J., \& Dahm, M. (2010). Rent seeking and rent dissipation: a neutrality result. Journal of Public Economics (forthcoming).

Andreoni, J. (1990). Impure altruism and donations to public goods: a theory of warm-glow giving. Economic Journal, 100(401), 464-477.

Bagnoli, M., \& Lipman, B. L. (1989). Provision of public goods-fully implementing the core through private contributions. Review of Economic Studies, 56(4), 583-601.

Bagwell, L. S., \& Bernheim, B. D. (1996). Veblen effects in a theory of conspicuous consumption. American Economic Review, 86(3), 349-373.

Baik, K. H. (1994). Effort levels in contests with asymmetric players. Southern Economic Journal, 61(2), 367-378.

Baik, K. H. (2005). Endogenous timing and effort levels in two-player asymmetric contests. Mimeo, Sungkyunkwan University.

Baik, K. H., \& Shogren, J. F. (1992). Strategic behavior in contests: comment. American Economic Review, 82(1), 359-362.

Barzel, Y. (2000). Property rights and the evolution of the state. Economics of Governance, 1(1), $25-51$.

Barzel, Y. (2002). A theory of the state. Cambridge: Cambridge University Press.

Batina, R. G., \& Ihori, T. (2005). Public goods, theory and evidence. New York: Springer.

Baye, M. R., Kovenock, D., \& de Vries, C. G. (1996). The all-pay auction with complete information. Economic Theory, 8, 291-305.

Benson, B. L. (1988). Legal evolution in primitive societies. Journal of Institutional and Theoretical Economics, 144(5), 772-788.

Benson, B. L. (1989). The spontaneous evolution of commercial law. Southern Economic Journal, 55(3), 644-661.

Bergstrom, T. C., Blume, L., \& Varian, H. (1986). On the private provision of public goods. Journal of Public Economics, 29, 25-49.

Bénabou, R., \& Tirole, J. (2006). Incentives and prosocial behavior. American Economic Review, 96(5), $1652-1979$.

Cornes, R. (1993). Dyke maintenance and other stories: some neglected types of public goods. Quarterly Journal of Economics, 108(1), 259-271.

Davis, D. D., \& Reilly, R. J. (1999). Rent-seeking with non-identical sharing rules: an equilibrium rescued. Public Choice, 100(1-2), 31-38.

De Meza, D., \& Gould, J. R. (1992). The social efficiency of private decisions to enforce property rights. Journal of Political Economy, 100(3), 561-580.

Elster, J. (1989). The cement of society: a study of social order. Cambridge: Cambridge University Press.

Esteban, J., \& Ray, D. (2001). Collective action and the group size paradox. American Political Science Review, 95(3), 663-672.

Falkinger, J. (2006). Non-governmental public norm enforcement in large societies. CESifo Working Paper No. 1368 (revised).

Fearon, J. D. (1995). Rationalist explanations for war. International Organization, 49, 379-414.

Fearon, J. D. (2008). Self-enforcing democracy. Mimeo, Stanford University.

Garfinkel, M. R., \& Skaperdas, S. (2007). Economics of conflict, an overview. In T. Sandler \& K. Hartley (Eds.), Handbook of defense economics (Vol. 2, pp. 649-710).

Glazer, A. (2002). Allies as rivals: internal and external rent seeking. Journal of Economic Behavior and Organization, 48(2), 155-162. 
Glazer, A., \& Konrad, K. A. (1996). A signaling explanation for private charity. American Economic Review, $86,1019-1028$.

Gradstein, M. (2007). Inequality, democracy and the protection of property rights. Economic Journal, 117(516), 252-269.

Grossman, H. I. (1994). Production, appropriation, and land reform. American Economic Review, 84, 705712.

Hardin, R. (1995). One for all: the logic of group conflict. Princeton: Princeton University Press.

Hirshleifer, J. (1983). From weakest link to best-shot: the voluntary provision of public goods. Public Choice, $41,371-386$.

Hirshleifer, J. (1988). The analytics of continuing conflict. Synthese, 76, 201-233.

Hirshleifer, J. (1994). The dark side of the force. Economic Inquiry, 32, 1-10 (reprinted in: Hirshleifer, J. (2001). The dark side of the force: economic foundations of conflict theory. Cambridge: Cambridge University Press).

Hirshleifer, J. (1995). Anarchy and its breakdown. Journal of Political Economy, 103, $26-52$.

Holcombe, R. G. (2004). Government: unnecessary but inevitable. The Independent Review, 8(3), 325-342.

Johnsen, D. B. (1986). The formation and protection of property rights among the Southern Kwakiutl Indians. Journal of Legal Studies, 40(1), 41-67.

Kaplan, T. R., Luski, I., \& Wettstein, D. (2003). Innovative activity and sunk cost. International Journal of Industrial Organization, 21(8), 1111-1133.

Katz, E., \& Tokatlidu, J. (1996). Group competition for rents. European Journal of Political Economy, 12(4), 599-607.

Konrad, K., \& Leininger, W. (2007). The generalized Stackelberg equilibrium of the all-pay auction with complete information. Review of Economic Design, 11, 165-174.

Kurrild-Klitgaard, P. (2002). Opting-out: the constitutional economics of exit. American Journal of Economics and Sociology, 61(1), 123-158.

Landa, J. T. (1994). Trust, ethnicity, and identity, beyond the new institutional economics of ethnic trading networks, contract law, and gift exchange. Ann Arbor: The University of Michigan Press.

Leeson, P. T. (2006). Efficient anarchy. Public Choice, 130, 41-53.

Leeson, P. T. (2007a). Trading with bandits. Journal of Law and Economics, 50, 303-321.

Leeson, P. T. (2007b). An-arrgh-chy: the law and economics of pirate organization. Journal of Political Economy, 115(6), 1049-1094.

Leeson, P. T. (2008). Coordination without command: stretching the scope of spontaneous order. Public Choice, 135, 67-78.

Leininger, W. (1993). More efficient rent-seeking—a Münchhausen solution. Public Choice, 75(1), 43-62.

McGuire, M. C. (1974). Group size, group homogeneity, and the aggregate provision of a public good under Cournot behavior. Public Choice, 18, 107-126.

McGuire, M. C., \& Olson, M. (1996). The economics of autocracy and majority rule: the invisible hand and the use of force. Journal of Economic Literature, 34(1), 72-96.

Müller, H. M., \& Wärneryd, K. (2001). Inside versus outside ownership: a political theory of the firm. RAND Journal of Economics, 32(3), 527-541.

Myerson, R. B. (2008). The autocrat's credibility problem and foundations of the constitutional state. American Political Science Review, 102(1), 125-139.

Nitzan, S. (1991). Collective rent dissipation. Economic Journal, 101, 1522-1534.

Olson, M. (1993). Dictatorship, democracy, and development. American Political Science Review, 87(3), $567-576$

Oppenheimer, F. (1908). Der Staat. Frankfurt am Main: Literarische Anstalt.

Orenstein, H., Ake, C., Cooper, E., Holzberg, C. S., Krader, L., Kurtz, D. V., Liep, J., Oshima, K., \& Wong, D. H. (1980). Asymmetrical reciprocity: a contribution to the theory of political legitimacy [and comments and reply]. Current Anthropology, 21(1), 69-91.

Powell, B. W., \& Stringham, E. P. (2009). Public choice and the economic analysis of anarchy: a survey. Public Choice, 140, 503-538.

Riker, W. (1966). Federalism. New York: Little Brown.

Sahlins, M. D. (1963). Poor man, rich man, big-man, chief: political types in Melanesia and Polynesia. Comparative Studies in Society and History, 5(3), 285-303.

Sánchez-Pagés, S., \& Straub, S. (2006). The emergence of institutions. Discussion Paper 148, University of Edinburgh.

Shen, L. (2007). When will a dictator be good? Economic Theory, 31(2), 343-366.

Skaperdas, S. (1992). Cooperation, conflict and power in the absence of property rights. American Economic Review, 82, 720-739.

Skaperdas, S. (2002). Warlord competition. Journal of Peace Research, 39(4), 435-446. 
Slantchev, B. L. (2003). The power to hurt: costly conflict with completely informed states. American Political Science Review, 97(1), 123-133.

Spolaore, E., \& Alesina, A. (2002). War, peace and the size of countries. Mimeo, Brown University.

Stringham, E. (2003). The extralegal development of securities trading in seventeenth-century Amsterdam. The Quarterly Review of Economics and Finance, 43, 321-344.

Tullock, G. (1972). The edge of the jungle. In G. Tullock (Ed.), Explorations in the theory of anarchy. The Public Choice Society Book and Monograph Series, Blacksburg, VA, USA (pp. 65-75). Reprinted in: E. Stringham (Ed.) (2005). Anarchy, state and public choice. Cheltenham: Edward Elgar.

Wärneryd, K. (1998). Distributional conflict and jurisdictional organization. Journal of Public Economics, $69,435-450$. 